\title{
Arvo Krikmann
}

\section{INFOTEHNOLOOGIA MINU ELUS'}

Kinnismõtet mul tegelikult ei ole, pigem on kinnistunne või -emotsioon.

See tunne on õnnetunne, ja see on esimene asi, mida ma viimase 7-8 aasta jooksul ütlen, kus ja millal iganes ma üldse suu lahti teen. Ning asi pole pelgalt ütlemises. Mind läbib tõesti tegelik ja terav ónneimpulss, kui ma hommikul silmad lahti teen ja mulle tulevad meelde kaks asja: nõukogude võimu ei ole, aga arvutid on.

Nõukogude võimu ei ole, nende lennukid ei lenda enam meie taevas, nende soldatid ei hulgu meie tänavatel, Saaremaa eestlastel pole vaja luba näidata, et koju saada.

Arvutid on, ma ise istun iga päev tundi paarteist päris hea arvuti taga, võtan teda kui vana sõpra, ja kõikjal mu ümber on neid kümnete kaupa - igas toas kirjandusmuuseumis, mis on olnud mu põhitöökoht peaaegu läbi elu.

Ma olen silmini õnnelik oma 62 eluaastast hoolimata.

Ja s-tähega haigusest hoolimata.

Ja sellest hoolimata, et kõigest hoolimata suitsetan ma nagu korsten.

Ja sellest hoolimata, et illusioone ja isiklikku tulevikku on ees tõenäoliselt üsna vähe.

Ja sellest hoolimata, et teadlaste ja üldse haritlaste käsi ei käi Eestis kuigi hästi ja teaduse rahastamine tammub juba mitu aastat paigal.

Ja sellest hoolimata, et Eestis on üldse liiga palju vaeseid ja nad on liiga vaesed, ja liiga vähe rikkaid ja nad on liiga rikkad. 
Ja sellest hoolimata, mis toimub ümber kõigi kurikuulsate raudteede ja elektrijaamade ja muude, loodan ma ikkagi, et Eesti ei ole oma varade mahamüümisega nii kaugel, et kriitiline punkt oleks juba ületatud.

Ja sellest hoolimata, et monopolid muutuvad meil iga päevaga ülbemaks ja nende vastu on raske rohtu leida ja et bürokraatia lokkab - sageli eurodirektiividele viidates - ja üks korruptsiooniskandaal sõidab teisel lausa seljas.

Ja sellest hoolimata, et Euroopa Liidu, kuhu me praegu suure rüsinaga tormame, ja Nõukogude Liidu, kust me alles üleeile välja saime, vahel ei ole ainult diametraalsed erinevused, vaid mõndagi sarnast.

Ja sellest hoolimata, et Eesti telekast tuleb groteskset reklaami, mis annab mõista, et sünnitav ema on sama hea kui korgipüss.

Ja hoolimata veel paljust muust.

Pole õige, et nõukogude võimul ja arvutitel pole teineteisega suurt sisulist pistmist. On vägagi. Nõukogude võim tabas väga hästi ära selle, et kes kontrollib informatsiooni ja selle levikut, kontrollib praktiliselt kogu olukorda. Ka kirjutusmasin oli info paljundamise vahend. Mäletan väga hästi aega, mil arvati (või vähemalt väideti), et rahvavaenlane virgub ja aktiviseerub just suurte riigipühade ajal, st 7. novembri ja 1. mai paiku. Siis tuli kirjutusmasinad viia selleks ettenähtud rauduksega ruumi, mille uksele pandi pühade ajaks pitser peale. Pärast pühi tassiti masinad jälle tööruumidesse laiali.

Kirjandusmuuseumi koosseisus on kolm suurt arhiivi, ja loomulikult on arhiivis vaja kogu aeg massiliselt kõike kopeerida. Me teadsime, et NEIL seal on kseroksid ja kõik, mis vaja. Aga kirjandusmuuseum sai oma esimese kseroksi vist 1990. aastate alguseks sakste vana, sedagi tänu Ingrid Rüütli isiklikule initsiatiivile ja välismaistele tutvustele n-ö humanitaarabi korras. Keele ja Kirjanduse Instituudis oli juba 1980. aastail valguskoopiamasin - vene oma, väga 


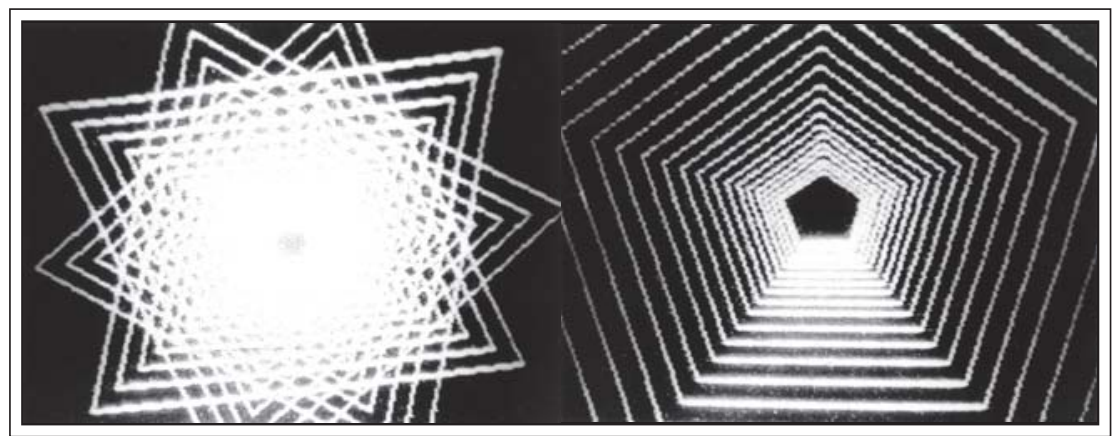

Foto 1. Hulknurksed kriksatrullid. Jaak Krikmanni foto 1987.

suur ja romsa. Musti plekke ta veidi jättis, kuid kopeeris üsna kiiresti. Aga see tuba, kus masin asus, oli peaaegu eriosakond, kopeerimistööd tegid selleks ettenähtud spetsialistid ja kõige üle, mida kopeeriti, peeti ranget arvestust ja kontrolli.

Arvestus, arvestus - hahhahhaa! Mäletan, et jäin 1963. aasta kevadel vist kuu aega hiljaks oma esimese lapse registreerimisega ja mind kutsuti koos teiste patustega range komisjoni ette "vaibale". Vabandasin ette ja taha ja vist julgesin küsida, kas kiirus on neis asjus siis nii oluline. Range tädi ütles mulle range vene aktsendiga: Aza лис ютлес Владилир Ильч? АРВЕСТУС, АРВЕСТУС, я виел корд APBECTYC!

Aga arvutid...

Praegu tagantjärele on üsnagi lustiline meenutada meie toonaseid "infotehnoloogilisi" võimalusi ja arvutusvahendite tulekut minu isiklikku ellu üldse. Arvutid kui sellised olid 1960. aastate algupoolel tavainimese jaoks ulme, poolmüütiline teispoolsus, millega määrati Juri Gagarinile, Nõukogude tuumarakettidele jm tähtsatele asjadele nende heroilisi orbiite. Tavainimeste elus oli kõik palju primitiivsem. Aga meie tegime just sellal oma eesti vanasõnade teaduslikku väljaannet, meil oli kindel nõu varustada see väljaanne sõnaregistriga ja me tahtsime registri tekitamist endale kiiremaks ja lihtsa- 
maks teha. Perfokaardid olid tollal kuum infotöötlusvahend ja me teadsime, et ajaloolane Heldur Palli on nende kasutamise alal suur fänn ja meister. Eesti vanasõnades on vanasõnad esitatud tüübiartiklite kaupa - seal on iga eri vanasõna eri üksus, eri "number", eri pealkirjaalune osa: Kes ees, see mees kohta on eraldi artikkel ta tekstide ja kommentaaride jaoks; Igal oinal oma mihklipäev - selle esitamiseks oma artikkel; Parem suutäis soolast kui maotäis magedat kohta on eraldi artikkel jne.

Käisin Heldur Palli jutul ja leppisime kokku, et vanasõna-artiklite tööeksemplarid kirjutatakse igaüks eraldi perfokaardile ja kaardi servale tehakse sälgud tähtsamate sõnade jaoks, mis igas vanasõnas ette tulevad: oinas ja mihklipäev ja soolane ja mage jne. Keeles on ju sõnu palju ja H. Palli soovitas seepärast valida kaardile suure formaadi - A4. Aga sõnu oli ikkagi lootusetult palju ja auke A4-kaardi servas ikka lootusetult vähe. Siis otsustati, et mõned eriti sagedased sõnad saavad oma eriaugu ja teised tähistatakse ainult alfabeedipiirkonna täpsusega - umbes nagu valimiskomisjonis: A-st I-ni ja J-ni ja K eraldi jne.

Jumal tänatud, et me ei hakanud selle meetodi järgi tööle - ei hakanudki neid kaardiservi iial sälkama. Kuigi kahjuks ei taibanud me juba ette, et see oli surnult sündinud mõte. Meie häda - või õnn - oli selles, et osa tüübiartikleid tulid nii pikad, et ei mahtunud suure perfokaardi kahelegi küljele ära ja tuli võtta appi lisalehti, ja me ei usaldanud hakata seda patakat enam laiali jagama, nii et perfod või esilehed eraldi ja lisalehed eraldi - sellest oleks tekkinud kirjeldamatu kaos.

Sellest, mis on perfokaartidega töötamine, sain ma aru alles 1970. aastate keskpaiku, kui mul jätkus ogarust hakata rajama eesti vanasõnade geograafilise leviku statistikat samuti perfokaartidele. Need kaardid olid, tõsi küll, poole väiksemad - A5, st pool tavalist kirjapaberilehte. Sest kihelkondi on Eestis ikkagi palju vähem kui sõnu eesti 


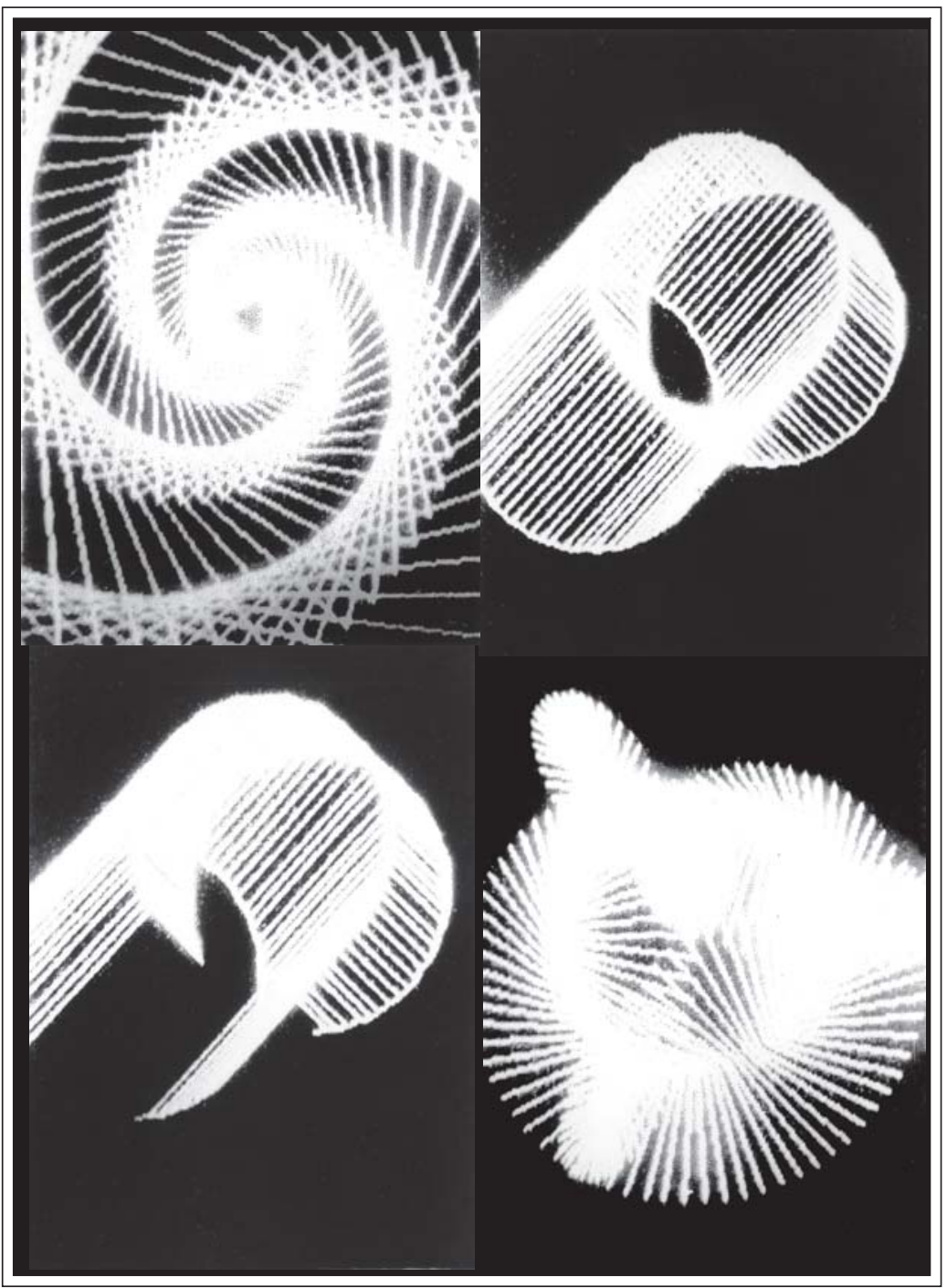

Foto 2. Mitmesuguseid siinusfunktsioonilisi kriksatrulle. Jaak Krikmanni foto 1987.

keeles - ainult veidi üle saja. Iga vanasõna sai jälle eraldi perfo. Ma lugesin iga vanasõna kohta näpuga kokku, millistest kihelkondadest kui palju teda on üles kirjutatud ja kirjutasin need andmed kaartide peale. Siis läks sälkamiseks: otsid spikriga õiged kohad üles ja teed 


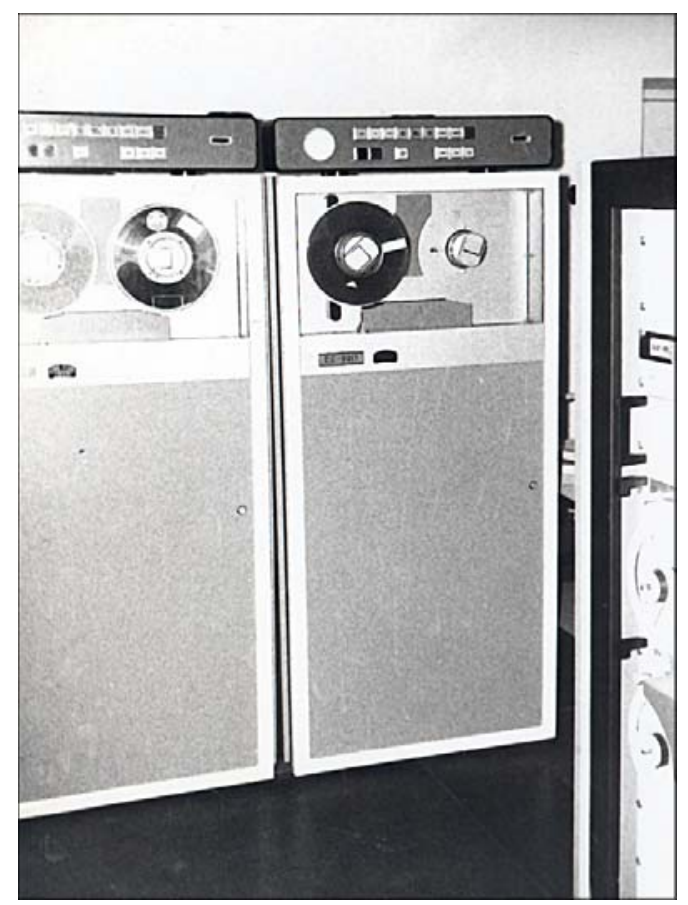

Foto 3. Imemasin EC-1010

Eesti Keele Instituudis. 1979. EKI arhiiv.

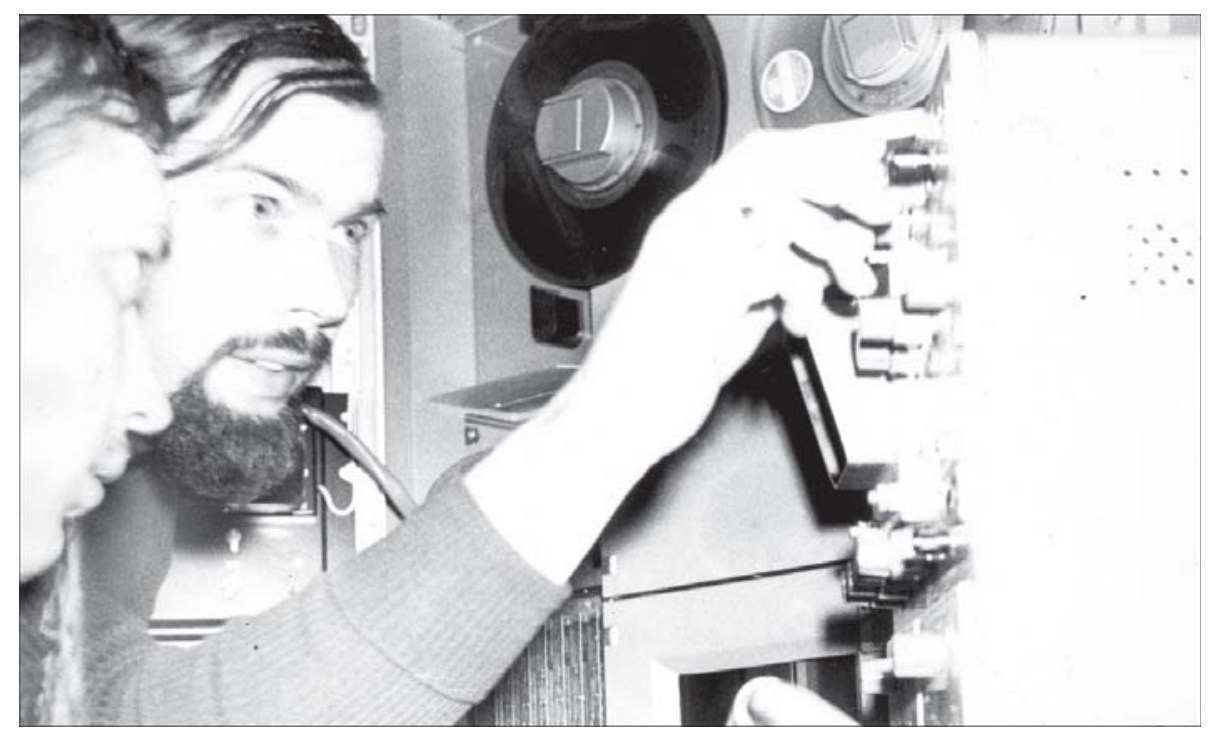

Foto 4. Maidu Piirmets ja Toomas Tago parandavad EC-1010-t. 1979. EKI arhiiv. 
sälgud. Õigeid sälkamistange polnud ka saada, keegi hea inimene andis nõu, et hädaga käivad ka need, millega vasikatel kõrvu narmastatakse. Ligi 5000 selgus olevat selliseid vanasõnu, mida oli üles kirjutatud rohkem kui ühest kihelkonnast, kõik need sälkisin ma hoole ja armastusega läbi. Mulle oli selle tähtsa töö juurde appi antud isegi - esma- ja ainukordselt mu elus üldse - midagi isikliku laborandi taolist. Nägin küll, et suurte ülemaalise levikuga tüüpide perfod meenutasid mingit narmastega vaipa, kui olin nende kallal lõpetanud, aga lootsin ikka, et see ei sega tööd.

Oli vaja ära hinnata seosetihedus kihelkonnapaaride vahel, st välja selgitada, kui mitu ühist vanasõna on igal kihelkonnapaaril. See pidi käima nii, et paned varda mingi "emakihelkonna" esimese partneri auku ja need vanasõnad, mis on seal kihelkonnas samuti olemas, kukuvad pakist välja; siis võtad selle väljakukkunute paki ja loed kaardid kokku. Ja nii ka iga järgmise partneriga. Ja siis võtad järgmise "emakihelkonna", ja jälle algab kõik, algab uuesti...

Kartoteek sai valmis ja ma asusin suure entusiasmiga kihelkondade ühisosi välja selgitama. Esimese poole tunni jooksul sai selgeks, et mäng ei vääri küünlaid. 5000 perfot on mitu head kastitäit. Aga see kaardipakk, mis korraga raputamisel oli, ei tohtinud olla paksem kui paar sentimeetrit, vastasel korral ei pudenenud välja kõik kaardid, mis pidanuksid pudenema. Seda õhukestki pakki tuli varda otsas raputada umbes nii jõuliselt, nagu raputatakse õunapuud - ja ikkagi ei tulnud kõik välja. Ning juba paari esimese sorteerimise järel läksid narmad kahekorra ja ühtede kaartide narmad läksid teiste aukudesse, kaardid haakusid lootusetult üksteise külge ja kitsamad sälguvahed murdusid lahtiharutamisel lihtsalt ära.

Lühidalt öeldes, minu meeleheide oli väga suur, kuid õnneks asutas Mart Remmel 1977. aastal Keele ja Kirjanduse Instituuti (KKI) arvutuslingvistika sektori ja hankis sinna järgmisel aastal Ungari päritolu arvutilahmaka Videoton. See võttis KKI Rävala puiestee majas 
enda alla suure saalitäie ja räägiti, et kõik kollektiivid, kuhu selline pill on tekkinud, on ennast varsti surnuks joonud, sest arvutiga käis kaasas nii tohutu piiritusenorm, millest õnnestus ainult tühine murdosa arvuti puhastamiseks ära kulutada. FORTRAN oli tollal see keel, mida Videoton hästi oskas. Kuvarile kirjutati programm, kanti see perfolindile ja lasti lint läbi arvuti hammaste - siis ta teadis, mis ta peab tegema. Aga tollases Nõukogude Liidus oli õnn omada omaenda arvutit ühele filoloogiainstituudile tohutu ime ja sektorijuhataja Mart Remmel - praegu juba manalamees - polnud üksnes geniaalne keeleteadlane ja programmeerija, vaid ka geniaalne organisaator.

Sinna Videotoni sisestati siis ka arvandmed eesti vanasõnade geograafilise leviku kohta, Jüri Kaldmaa tegi ühisosade arvutamiseks programmi (Assembleris, nagu mäletan) ja elu sai uuesti värvid.

Veel aastal 1980, kui hakati sõitma Turgu fennougristika kongressile, elasin ma mitu nädalat Tallinnas, sest pidin oma vanasõnastatistikate kohta kongressil ettekande tegema. Videoton printis ka - servast perforeeritud rulli peale, kandes sellele ühesuguste ja ühesuuruste tähemärkide abil kõik kirjad ja joonised ja mis iganes tekitati. Meelis Mihkla tegi mulle selle printeriga regressiooniväljade n-ö punktipilvede - graafikuid. Need olid oma neli meetrit pikad ja kui ma tahtsin silma järgi hinnata, kas välja üldkuju on enam-vähem lineaarne, oli kõige targem selle tapeedipaani ühe otsa juurde kõhuli lasta ja niimoodi lähedalt terava nurga alt vaadata.

Mul on üldse kogu aeg olnud nostalgia teha igasugu statistikaid ja see on toonud mulle palju suurt ja helget õnne. Mu kõige esimesed statistikad käisid regilaulu alliteratsiooni kohta, hakkasin neid tegema juba kunagi 1960. aastate keskel. Arvutuslükati andis kolm kohta pärast koma, mulle tundus, et see pole piisavalt täpne (tegelikult oleks käinud küll), niisiis tegin oma esimesed suured pikad rehkendused 1960. aastate lõpupoolel Vladimir Bradise legendaarsete logaritmitabelitega. 
Aastal 1974 hakkasin Ringtee tänavas Tartu Filmilaenutuse Baasis valvurina leivalisa teenima, sest valmistusin kaitsma oma kandidaaditööd ning selleks oli vaja ülikonda ja suutlikkust korraldada tollal enam-vähem obligatoorne kaitsmispidu. Minu valvamiskoht oli sekretäriruumis ja sekretäri laual oli tohutu suur elektromehaaniline ragisti, mis oli võimeline mitte ainult summeerima, vaid kui tal oli hea tuju, siis ta ka korrutas ja jagas. Võtsin lühikese piinarikka häbenemise järel oma mehisuse kokku ja küsisin raamatupidajalt, kas tohiksin sellega öösiti veidi arvutada, ja ta lubas. Logaritmitabeliga võrreldes oli kiirusetaju lausa ekstaatiline ja ma veetsin selle ragistaja taga palju õnnelikke öid.

Siis tulid üsna pea mu ellu kalkulaatorid. Esimest kalkulaatorit nägin vist 1975. aasta suvel Lembit Valdi käes, see oli imetilluke ja klahvid liiati nii väiksed, et neid tuli vajutada tuletikuotsaga. Nagu öeldud, hakkasin siis just oma kandidaaditööd kaitsma ja L. Valt oli üks minu kolmest oponendist. Too väitekiri oli iseendast samuti suur imetegu. Jutt käis vanasõnade semantika ja maailmavaate ümber, ja kõik nõukogude autorid, keda ma oma tööd kirjutades lugesin, väitsid ühest suust, et vanasõnad on oma maailmavaate poolest ligikaudu naiivne marksism ja stiihiline ateism. See oli liiga rumal, et sellega nõus olla või seda teooria plaanis aluseks võtta. Aga tollane ainus lubatud võimalus kedagi rumalat lüüa oli lüüa teda Marxi või Leniniga. Mina nuputasin samuti imetrikke, et oma rumalaid Marxi ja Leniniga lüüa, ja see läks mul enda meelest ka korda. Aga kaitsmisel tabas valvsate nõukogu liikmete klassivaist ikkagi kena marksistliku maski tagant mu rahvavaenuliku olemuse ära - sain kolm või neli vastuhäält ja oleksin peaaegu läbi kukkunud.

Siis 1976. aasta sügisel, kui Mart Remmel oli otsustanud mind oma arvutuslingvistika sektorisse tööle võtta, juhtus midagi täiesti fantastilist - ta saatis mulle Tartusse Vene kalkulaatori Elektronika. See oli tubli videokasseti mõõtmetega karp, mis tegi nelja tehet ja 
läks alati lolliks just siis, kui sul oli, ütleme, 113 arvust 111 summeeritud. Kuid ikkagi oli see jälle uus pikk samm täiusliku õnne poole.

See vanasõnaprojekt, mille külge mind 1964. aastal haagiti, oli tegelikult suur Soome-Eesti koostööprojekt, mille Matti Kuusi, tuntud soome folklorist ja vanasõnauurija, 1963. aasta lõpul algatas suur ime tolle aja kohta, liiati ka edukas ja pikaajaline. Töö käis tavaliselt nii, et kui oli vaja kohtuda, tulid soomlased Tallinna. Tartusse neid ei lastud, sest Tartus oli sõjaväelennuväli. Ja meid Helsingisse ka ei lastud - noh, või PEAAEGU ei lastud, vahel fennougristika kongressidele ikka lasti.

Jaanuaris 1979 juhtus siiski see suur ime, et mul ja Ingrid Sarvel lubati sõita Helsingisse koguni 20 päevaks, ja mitte ainult et lubati, vaid anti isegi komandeering, ilmatu pihutäis Soome raha jne. Sõit käis muidugimõista rongiga Moskva kaudu. Moskvas on Nikitnikovi põiktänav (Nikitnikov pereulok), kus asus Teaduste Akadeemia nn välisosakond. Meile anti seal allkirja vastu vajalikke salajasi käitumisbrošüüre lugeda, ja siis tuli vestelda veel spetsialistiga. Põhispetsialist, ütleme, Petrov, oli juhtumisi kuskil ära, teda asendas, ütleme, Sidorov. Sidorov küsis: Kmo makue? Kyda? По kakoлy nobody? jne. Meie ütlesime, et uurime vanasõnu ja teeme soomlastega koostööd. Sidorov hingas sügavalt sisse, ütles: Да, пословииь - это, на первый взгляд, предлет довольно-таки безбинный. НО... - ja loetles uтbes kümme minutit vanasõnadesse kätketud ideoloogilisi ohtusid. Ühtki ohtu ennast mul enam meeles pole, kuid mäletan, et noogutasime iga ohu juures entusiastliku soostumusega.

Sel Helsingis-käigul keegi - ma ei teagi, kas Kari Laukkanen (meie projekti üks Soome poole põhitegijaid Matti Kuusi kõrval) või Soome Kirjanduse Selts Kari Laukkase käe läbi - keegi igatahes kinkis mulle programeeritava kalkulaatori Texas Instruments 57, millel oli kümme mälupesa ja võimalus kirjutada 50-käsuline programm, ilgetes numbrikoodides muidugi. Nii õnnelik kui siis, pol- 
nud ma vist eales enne olnud. Too hüperkompuuter oli üldse statistilise orientatsiooniga ja suutis arvutada ka nt lineaarse regressiooninormi parameetreid.

Kari Laukkanen hakkaski mulle kalkulaatori-samariitlaseks ja paar aastat hiljem sain jälle tema kaudu uue, veelgi võimsama kalkulaatori, vist Texas Instruments 58C. Tollel oli juba jagatav mäluruum: võisid valida, kas võtsid palju andmemälu ja said kirjutada ainult lühikese programmi, või vastupidi, või midagi vahepealset. See riist teenis mind ausalt mitu aastat ja ma tegin temaga suuri asju.

Tegelesin ka tollal levikukaartidega, sh püüdsin selgitada Heinrich Gösekeni, Salomo Heinrich Vestringi ja Anton Thor Helle kirja pandud vanasõnade võimalikku geograafilist tausta. Sellistel puhkudel on kasulik mingeid koefitsiente või andmeid

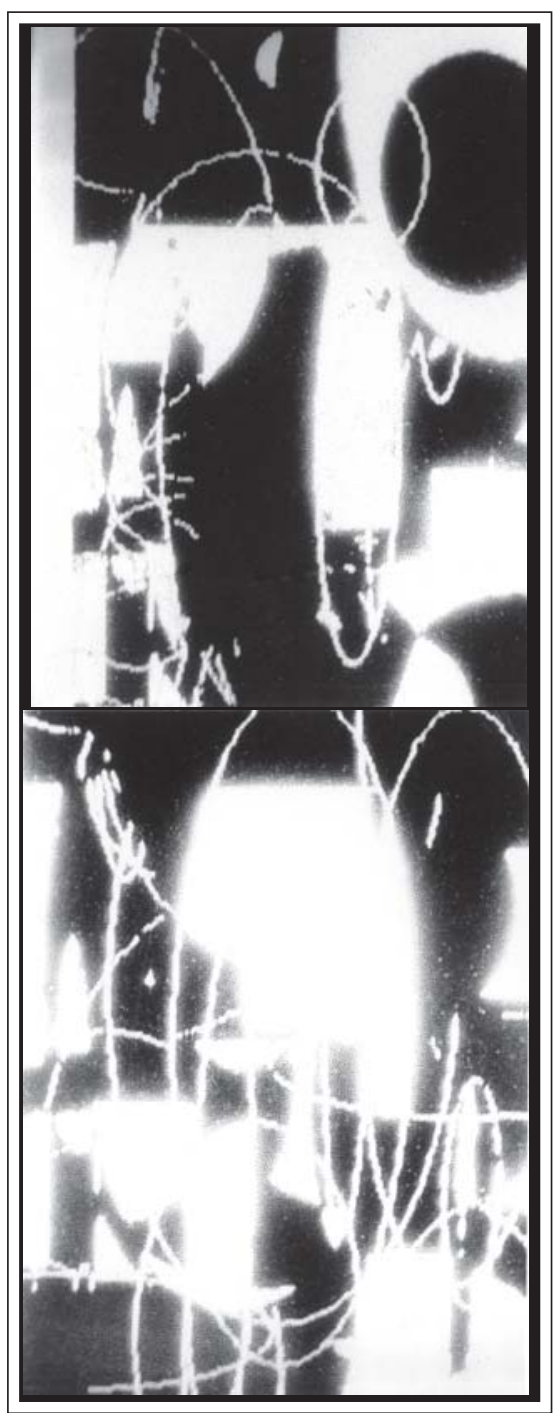

Foto 5. Ovaalidel põhinevaid kriksatrulle. Jaak Krikmanni foto 1987. siluda. Ütleme, sul on Nõos hunnik, Otepääl mägi, Kambjas nõgu, Puhjas lohk ja Tartu-Maarjas täielik tühjus, aga oleks tarvis saada asjast mingi ülevaatlikum pilt, n-ö Lõuna-Tartumaa piirkondlik keskmine. Siis on mõistlik toornäidud naa- 
berkihelkondade vahel ära siluda. Selleks on mitmesuguseid tehnikaid, loomu poolest meenutab operatsioon pahteldamist mitte eriti laia labidaga: mäed hõorrutakse allapoole ja lohud täidetakse ülespoole. Eestimaa sadakond kihelkonda mahtusid kalkulaatori mällu vaid osade kaupa, tulemused tuli loomulikult käsitsi mälust välja noppida ja üles kirjutada, kuid tehte kaupa toksimisega võrreldes oli ajavõit ikkagi määratu.

1987. aasta kevadel laenas Mart Remmel, mu kodumaine sponsor, mulle kuskilt Tartu Ülikoolist esmakordselt juba p ä r i s arvuti - Commodore-16. See koosnes tavalisest väikesest punasest Vene telekast ja paksust klaviatuurist, mille põhjas oli ka kogu ta tarkus - 12-kilobaidine hiigelmälu. Milline nauding oli istuda arvuti taga ja vaadata, käed risti rinnal, kuidas mu enda kirjutatud BASIC-programm tegi neidsamu kaardisilumisi täiesti omal jõul, tulemused tilkusid pikkamisi ekraanile ja mul oli vaja need ainult paberile üles kirjutada. Ja milline nirvaana - programmi polnud vaja enam otsast peale uuesti klahvistikult mällu tippida, vaid selle võis salvestada kassettmaki lindile ja kui vaja, sealt jälle peale laadida. Pikema programmi korral kulus selleks muidugi oma veerand tundi ja igal kolmandal korral teatas arvuti külmalt Break error!, ning tuli otsast alustada. Kummati tegi kommodoor umbes tunniga ära selle arvutustöö, mis kalkulaatoriga võttis mitu päeva (ja millele STATISTICA-programm mu praeguse arvuti peal kulutab umbes paar sekundit, joonistades lisaks vähem kui 10 sekundiga valmis ka tulemkartogrammi).

Muidugi sain üsna varsti aru, et 12 kilobaidi mäluga ei ole siiski võimalik midagi eriti tegelikku ära teha. Aga kui ilusaid liikuvaid geomeetrilisi figuure oli võimalik kommodooriga joonistada! Lõpuks söandasin konstrueerida isegi asju, mis meenutasid mingeid neandertaalseid arvutimänge - üks oli näiteks selline, kus tellise moodi nelinurgad kukkusid ekraanil suvalistest kohtadest allapoole ja nooleklahvidega võimeldes sai neist siis seina või torni laduda; kukkumise 


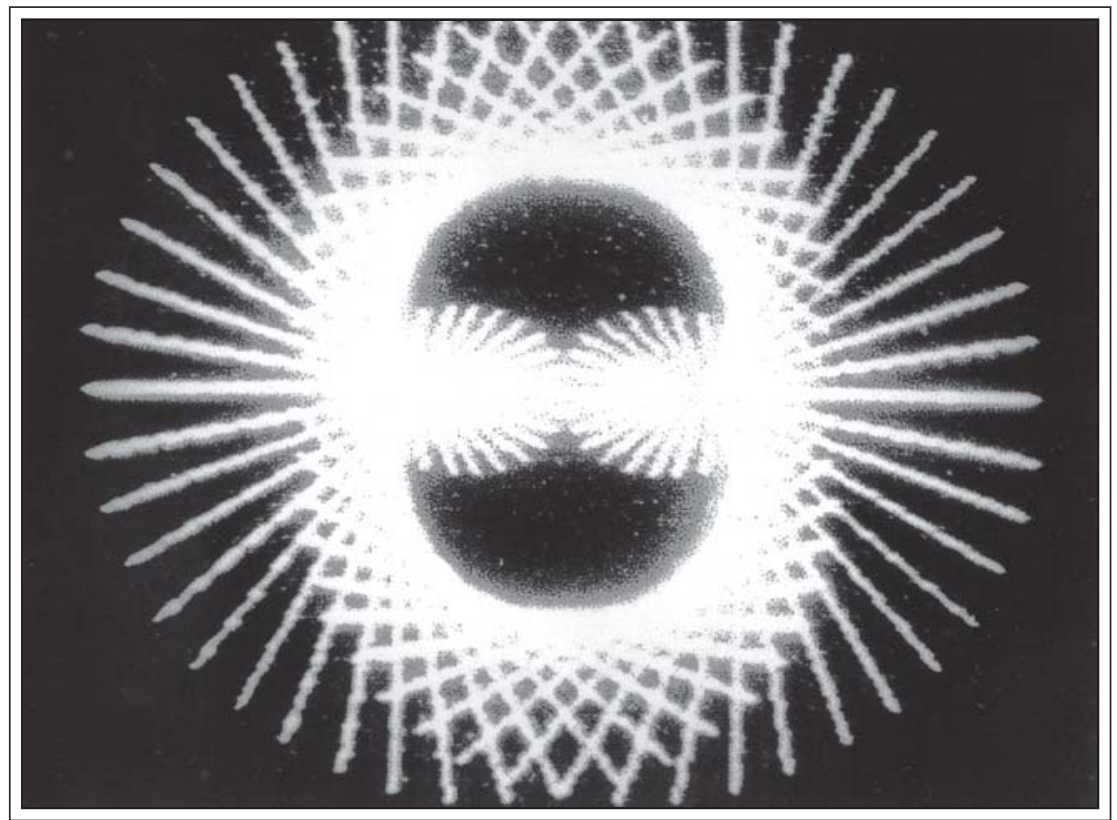

Foto 6. Veel üks siinuskriksatrull. Jaak Krikmanni foto 1987.

kiirus oli reguleeritav. Ehitasin neid seinu siira lapseliku lustiga, kuigi olin sellal juba 48 aastat vana. Vägilane ei olnud paraku minu oma, vaid Tartu Ülikoolilt laenatud, ja 1988. aasta kevadel tuli kuri onu, võttis klaviatuuri, maki ja teleka sülle ning läks oma teed.

Vist 1988.-1989. aasta talvel tegi üks mu poegadest katse osta endale Vene arvuti Kristi. See oli minu kommodoorist tunduvalt primitiivsem, ta oli oma põhiolekus täiesti tühi ja kogu intellekt tuli talle igaks uueks seansiks makilindilt sisse pumbata. Paaritunnise katsetamise järel läks ta lõplikult nässu ega osanud enam muud teha kui laliseda ekraanile: $Я$ - Кристи... $Я-$ - кисти... $я-$ - кристи... Õnneks võeti Kristi poodi tagasi.

Millalgi umbes samal ajal tekkis kirjandusmuuseumi kaks esimest arvutit - üks oli XT ja teine AT. See tekitas järjekordse illusioonilaine, et korraldatakse massilised arvutikursused, jagatakse os- 
kajatele ajad ja hakatakse suuri asju tegema. Anto Unt käis vist tõesti paar korda meil ning rääkis ja näitas midagi. Aga asi ei käivitunud ja tegelikult ei tehtud nende arvutitega iial praktiliselt midagi, ainult töötajate lapsed klõpsisid nendega tundida kaupa mänge mängida. Nüüd tean ammuilma, et arvutioskused ei asu üldsegi eelkõige peas, vaid n-ö kätes. Arvutiga suhtlemine on sedavõrd kiire ja efektiivne, kuivõrd hästi on kasutajal juurdunud vajalikud automatismid - ükskõik, kas nuppudele vajutamiseks või programmide kirjutamiseks või mõlemaks tegevuseks.

Veel kaks illusioonide purunemist tuli mul nõukogude võimu agoonia ajal üle elada. Minu haledate ja pidevate palumiste peale saatis Mart Remmel mulle Tallinnast lühikese aja jooksul kaks arvutitaolist eset - esimene Vene Omega ja teine Ida-Saksa Robotron. Omega suutis oma parimail hetkedel tekitada ekraanile ähmaseid trükitähti ja kui tungivalt palusid, joonistas ka pirnikujulisi ringjooni. Robotron ei läinud üldse käima.

Mäletan, kuidas ma kunagi 1990. aastate alguses kuulasin, suu ammuli, kui välismaadel olnud mehed rääkisid sealsetest arvutiimedest. Jaan Ross rääkis: on selline imeasi nagu e-mail; sa istud oma arvuti taga, kirjutad näiteks Austraaliasse kirja ja kümne minuti pärast võid saada vastuse; te võite isegi chat-režiimi minna ja dialoogivormis juttu ajada. Jüri Allik - samuti suur arvutiguru Eestis juba sügaval vene ajal, kõik etapid kaasa teinud, kõik nägurid ära näinud ja läbi raskuste tähtede poole trüginud - rääkis, kuidas USAs tudengid õpivadki põhiliselt arvuti taga ja saavad sealtkaudu oma õppematerjalid ning teadlased loevad arvuti kaudu oma kirjandust ja kui tahavad midagi tsiteerida, ei pea seda üldse pastakaga raamatust või ajakirjast maha kirjutama.

Vist 1992. aastast hakkasid Eesti Keele Instituudi Tartu folkloristika-poolele sugenema esimesed pärisarvutid. Mare Kõiva oli selle arvutiseerumise põhiline initsiaator. Tema poeg Sander Vesik, sellal 
alles koolipoiss, aga juba siis põline arvutifänn, oli meil vahepeal mitu aastat veebimeheks. Sander on tõesti väga geniaalne inimene, lahke meelega ja alati abivalmis pealekauba.

1994. aasta suvel sain minagi Avatud Eesti Fondi abiraha toel oma esimese pärisarvuti. Kuna aga just sel suvel evitati kirjandusmuuseumi nn uut maja ning kõik ruumid olid täis paksu tolmu ja potentsiaalseid vargaid, sain hakata oma imepilli mängima alles sügisel.

Aastail 1992-1993 võttis Eesti Teadusfond (ETF) juba enam-vähem jalad alla ja hakkas teadlastele süstemaatiliselt grante jagama. 1995 oli see aasta, millal meie maja folkloristid tegid suure kohaliku tiigrihüppe ja hankisid - just nimelt ETFi grandiraha abiga - kümmekond uut arvutit. Internet oli sellal maailmas juba mõnda aega olemas ja meilgi olid juba mõnda aega suured võrgurajamise illu-

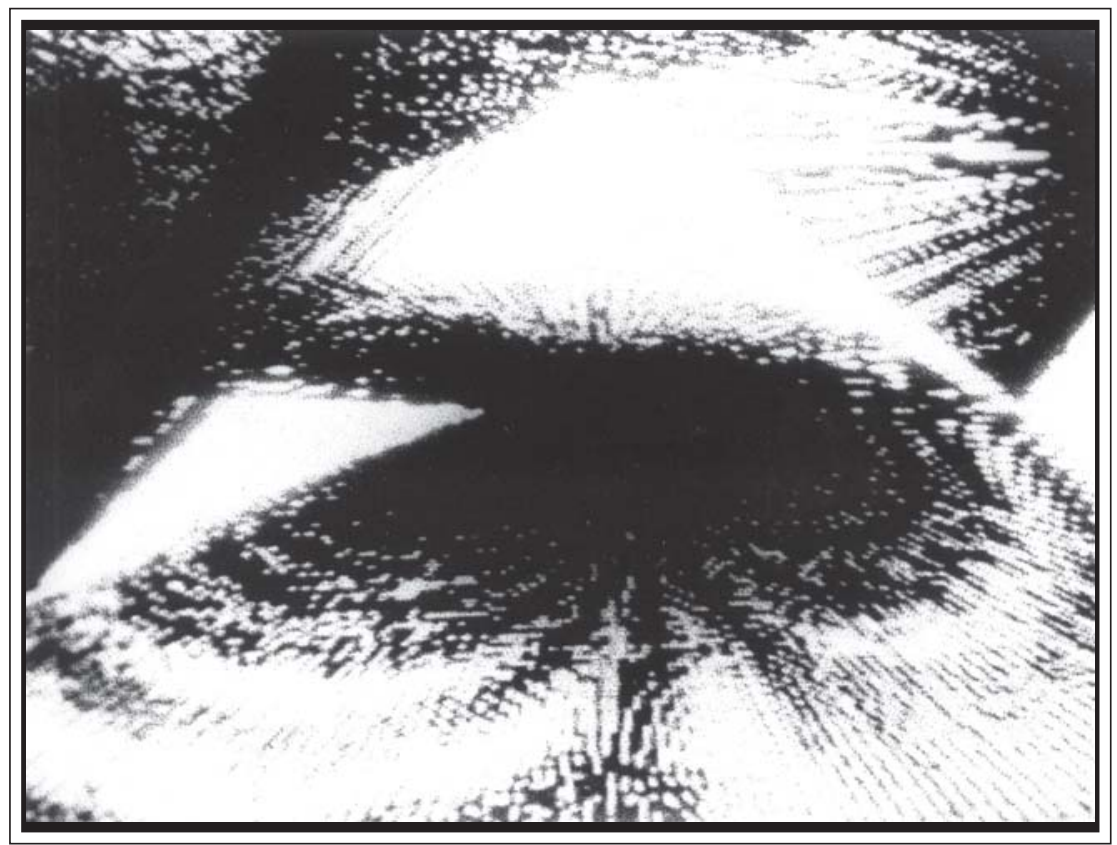

Joonis 7. Kriksatrull Seier ühes oma arengujärgus. Jaak Krikmanni foto 1987. 
sioonid, aga kümmekonnast arvutist oli päris võrgu jaoks vähe. Kuid meil oli hammas juba verel.

Siis tuli mängu Enn Vallak, Eesti aukonsul Šveitsis, ise suure kirjandusliku minevikuga mees. Ta käis Eestis, armus kirjandusmuuseumi, kuulis, et meil on arvutipuudus ning lubas meid aidata ja kinkida arvuteid. 1995. aasta hilissügisel läks asi tegelikuks. Jälgisime hinge kinni pidades nagu rindeteateid, kuidas tohutu rekka läbi Euroopa kulges, korraks Poolasse kinni jäi, siis vist veel Eesti tolli kinni jäi jne, jne. Aga lõpuks, mõned päevad enne jõule saabus see gigant kirjandusmuuseumi otsaukse juurde ja kümned südamed põksusid õnneootuses. Luuk tehti lahti - ja esimese pilguga sai selgeks, mis tegelikult oli toimunud. Firma, kellega E. Vallak oli seotud, oli vana meest petnud, transpordi peale tema raha raisanud ja Eestimaale lihtsalt oma utiili ära saatnud. Need olid 1980. aastate algupoolelt pärit, mitu korda remonditud XT-d, kokku ligi 40 tükki. Meil polnud nendega mitte midagi peale hakata.

Aga protsess oli juba peatumatult alanud. ETF jagas jätkuvasti grante ja meie arvutipark kasvas kiiresti. 1996. aasta talvel said Vanemuise tänava folkloristid arvutivõrgu. Kirjandusmuuseumi majja tekkis õieti kaks kohtvõrku, folkloristidele Haldjas ja maja ülejäänud ossa Kirmus. Kirjandusmuuseumil on hetkel kokku 88 arvutit ja mul on ülbust arvata, et Eesti humanitaaride "isiklikud" arvutioskused on keskeltläbi võib-olla paremadki kui reaalteadlastel, sest meile on arvuti olnud poolmütoloogiline ihalusobjekt, uue aja sümbol, neile aga lihtsalt tehniline abivahend.

\section{Kommentaar}

${ }^{1}$ Vikerraadio saatesarjas "Kinnismõte” 21. novembril 2001 esitatud veste. 


\section{VÕIM \& KULTUUR 2}

\section{Koostaja ja toimetaja Mare Kõiva}

http://www.folklore.ee/pubte/eraamat/voimjakultuur2/

Koostaja ja toimetaja: Mare Kõiva

Keeletoimetaja: Mare Kalda

Inglise keele toimetaja: Tiina Kirss

Makett ja kaas: Alo Paistik

Pilditöötlus: Andres Kuperjanov

HTML: Diana Kahre

ISBN 978-9949-586-83-7 (pdf)

ISBN 978-9949-418-53-4 (trükis)

DOI: $10.7592 / \mathrm{VK} 2.2006$

Tartu 2018

Trükis ilmunud: Võim \& kultuur 2. Koostaja ja toimetaja

Mare Kõiva. Võim ja kultuur. Tartu 2006

E-raamatu valmimist toetas: EKKM14-344 Eesti keele, kultuuri ja folkloori kasutusalade laiendamine ja tutvustamine elektroonilistel infokandjatel.
(C) 2018 Eesti Kirjandusmuuseum
(C) 2018 Eesti Folkloori Instituut
(c) 2018 EKM FO rahvausundi ja meedia töörühm
(C) 2018 autorid 